\title{
Relations between surgeons and industry: the time of clarification has come
}

\author{
M. Aebi · R. Gunzburg $\cdot$ F. Pellisé $\cdot$ \\ M. Szpalski
}

Accepted: 17 April 2008/Published online: 29 April 2008

(C) The Author(s) 2008

When S. Garfin has presented his thoughts about a year ago during a small seminary, it was not yet known that several spine surgeons had gotten into the crossfire of a US Senate investigation and hearing because of suspected conflicts of interest they were perhaps not even aware of. Equally MedTech companies active in our field of interest have been investigated and fined because of their relationship to doctors and medical organizations. It can be assumed that this kind of problem will be uncovered even more in the next future and that similar issues may arise also in Europe. Very damaging to the medical profession was the fact that potentially inappropriate conflicts of interest in joint arthroplasty [1] or spine surgery [2] have been revealed by major media like The New York Times before the profession has addressed them by itself. Additional reports that surgeons and/or institutions involved in clinical studies of spinal implants had investments in the manufacturer of said implants, and thus stood to gain financially from positive

\footnotetext{
M. Aebi $(\bowtie)$

Institute for Evaluative Research in Orthopaedic Surgery, University of Bern, Stauffacherstrasse 78,

3014 Bern, Switzerland

e-mail: max.aebi@MEMcenter.unibe.ch

R. Gunzburg

Eeuwfeestkliniek, Harmoniestraat 68,

2018 Antwerp, Belgium

F. Pellisé

Hospital Valle Hebron, P.V. Hebron 119-129,

08035 Barcelona, Spain

M. Szpalski

Hôpitaux Iris Sud/Molière Longchamp, 142, rue Marconi, 1190 Brussels, Belgium
}

results of their studies, further tarnished the image of spine surgery [3].

As a journal in the field of spine sciences we are aware of a mutual dependency of research-be it clinical or be it basic sciences-and industry, an alliance which has been extremely beneficial in the past for the advancement of better patient care. Yet, it carries equally a relevant risk of loosing scientific independency resulting in biased results.

We believe that we are only at the beginning of a basic debate and all those participating in this "industry-medical science-patient complex" need to better identify and understand their roles and seek for solutions, which still allow to foster medical progress while becoming more transparent and honest.

There is no doubt that a scientific journal as well as the professional scientific society in which's name it acts have to play their role in raising awareness on this fundamental problem.

To address this complex issue EuroSpine-the Spine Society of Europe (SSE) — has recently installed a Foundation: The EuroSpine Foundation. This will allow those directly involved (physicians, industry, possibly patients, authorities and other players in the health care market such as (e.g. insurances, etc.) to seek jointly innovative solutions. The goal is to maintain or even increase the resources from the different partners in order to better serve the ultimate purpose of improving patient care while making physicians and industry less vulnerable for questionable relationships.

A strucure like the EuroSpine Foundation is best placed to assist the Society's mission of fostering excellence in spinal care through education, research and quality assessment by sharing knowledge and expertise both amongst professionals and with industrial partners and the patients.

As we wrote earlier [4] it is in the interest of everyone, medical profession and industry, that the independence of 
basic scientists and surgeons involved in research and/or clinical practice is not the subject of suspicions.

As a contribution and stimulation for a lively discussion in our spine community we invited S. Garfin to write down the thoughts he expressed a year ago, and T. Steffen who is regularly involved as a researcher in technology transfer between academia and industry to offer his stand point of view. Both come to similar yet different conclusions in their contributions.

We hope sincerely to hear a lot of comments and suggestions from our readers.

Open Access This article is distributed under the terms of the Creative Commons Attribution Noncommercial License which permits any noncommercial use, distribution, and reproduction in any medium, provided the original author(s) and source are credited.

\section{References}

1. Abelson R (2005) Possible conflicts of interest are seen on medical devices. The New York Times, 22 September 2005

2. Abelson R (2006) Whistle blower suits says device maker generously rewards doctors. The New York Times, 24 January 2006

3. Abelson R (2008) Financial ties are cited as issue in spine study. The New York Times, 30 January 2008

4. Szpalski M, Gunzburg R, de Kleuver M (2003) Unethical research contracts: just say NO. Eur Spine J12:107 